Article

\title{
Evaluating Feruloyl Esterase-Xylanase Synergism for Hydroxycinnamic Acid and Xylo-Oligosaccharide Production from Untreated, Hydrothermally Pre-Treated and Dilute-Acid Pre-Treated Corn Cobs
}

\author{
Lithalethu Mkabayi $^{1}{ }^{(}$, Samkelo Malgas ${ }^{1}\left(\mathbb{D}\right.$, Brendan S. Wilhelmi ${ }^{2}\left(\mathbb{D}\right.$ and Brett I. Pletschke ${ }^{1, *(\mathbb{C}}$ \\ 1 Enzyme Science Programme (ESP), Department of Biochemistry and Microbiology, Rhodes University, \\ Grahamstown, Eastern Cape 6140, South Africa; lithalethum@gmail.com (L.M.); \\ samkelomalgas@yahoo.com (S.M.) \\ 2 Department of Biochemistry and Microbiology, Rhodes University, Grahamstown, Eastern Cape 6140, \\ South Africa; b.wilhelmi@ru.ac.za \\ * Correspondence: b.pletschke@ru.ac.za; Tel.: +27-46-6038081
}

Received: 4 April 2020; Accepted: 30 April 2020; Published: 13 May 2020

check for updates

\begin{abstract}
Agricultural residues are considered the most promising option as a renewable feedstock for biofuel and high valued-added chemical production due to their availability and low cost. The efficient enzymatic hydrolysis of agricultural residues into value-added products such as sugars and hydroxycinnamic acids is a challenge because of the recalcitrant properties of the native biomass. Development of synergistic enzyme cocktails is required to overcome biomass residue recalcitrance, and achieve high yields of potential value-added products. In this study, the synergistic action of two termite metagenome-derived feruloyl esterases (FAE5 and FAE6), and an endo-xylanase (Xyn11) from Thermomyces lanuginosus, was optimized using $0.5 \%(w / v)$ insoluble wheat arabinoxylan (a model substrate) and then applied to $1 \%(w / v)$ corn cobs for the efficient production of xylo-oligosaccharides (XOS) and hydroxycinnamic acids. The enzyme combination of $66 \%$ Xyn11 and 33\% FAE5 or FAE6 (protein loading) produced the highest amounts of XOS, ferulic acid, and $p$-coumaric acid from untreated, hydrothermal, and acid pre-treated corn cobs. The combination of $66 \%$ Xyn11 and 33\% FAE6 displayed an improvement in reducing sugars of approximately 1.9-fold and 3.4-fold for hydrothermal and acid pre-treated corn cobs (compared to Xyn11 alone), respectively. The hydrolysis product profiles revealed that xylobiose was the dominant XOS produced from untreated and pre-treated corn cobs. These results demonstrated that the efficient production of hydroxycinnamic acids and XOS from agricultural residues for industrial applications can be achieved through the synergistic action of FAE5 or FAE6 and Xyn11.
\end{abstract}

Keywords: Ferulic acid; Feruloyl esterase; Xylanase; Synergy; Xylo-oligosaccharides

\section{Introduction}

Lignocellulosic biomass is widely considered one of the most promising low-cost feedstocks for the production of renewable energy and value-added chemicals. It is primarily composed of three major components, namely: cellulose (40-60\%), hemicellulose (20-40\%), and lignin (10-25\%) [1] Waste agricultural residues generated during crop harvesting and processing (e.g., rice straw, wheat straw, corn stover, corn cobs, sugarcane bagasse, sorghum bagasse, etc.) are renewable biomass resources that are readily available and inexpensive [2]. A significant amount of research has focused on developing environmentally friendly methods of utilising lignocellulosic biomass. In this regard, enzymatic conversion has emerged as a major technological platform that offers several advantages 
such as environmental benefits and lower energy costs, with no formation of undesirable by-products. Due to the complexity and heterogeneity in the structure of biomass, its enzymatic conversion requires the synergistic cooperation of several enzymes [3]. A detailed understanding of this synergistic cooperation is key in the development of enzyme cocktails for the optimal production of value-added chemicals from lignocellulosic biomass.

Feruloyl esterases (FAEs, EC 3.1.1.73) and endo-xylanases (EC 3.2.1.8) are essential enzymes for the degradation of xylan, the most abundant hemicellulose in biomass. FAEs catalyze the cleavage of covalent ester linkages between hydroxycinnamic acids and polysaccharides, releasing ferulic acid (FA) and p-coumaric acid (p-CA) from lignocellulosic biomass [4,5]. FA, the most abundant hydroxycinnamic acid, is usually esterified at the C-5 hydroxy group of the arabinofuranosyl units of arabinoxylan of commelinid plants [6]. Hydroxycinnamic acids are used in the food industry as precursors for vanillin, $p$-hydroxybenzoic acid and 4-vinylphenol production, and as food preservatives because of their antimicrobial properties [7], while in the pharmaceutical industry, they can be used for their antioxidant and anti-inflammatory properties [8-11]. Application of FAEs not only releases hydroxycinnamic acid, but also decreases biomass recalcitrance, making it more accessible for further hydrolysis by carbohydrate-active enzymes [11]. Endo-xylanases are essential in degrading xylan as they catalyze the random cleavage of $\beta-1,4$-D-xylosidic linkages, generating xylo-oligosaccharides (XOS) [12]. The enzymes have been classified into glycoside hydrolase (GH) families 5, 8, 10, 11, 30, 43, 62 and 98, with GH10 and 11 being the two families that have been extensively characterized (www.cazy.org). Endo-xylanase generated XOS from agricultural residues are used in food, feed, and pharmaceutical industries due to their prebiotic and antioxidant activity [13,14].

FAEs exhibit a synergistic interaction with xylanases during the hydrolysis of a range of lignocellulosic substrates, which is demonstrated by improved yields in the production of XOS and FA. Xylanases generate ferulated XOS, which become preferred substrates for FAEs to cleave ester bonds from, liberating FA as a product [15]. The removal of FA then increases the accessibility of xylanases to XOS for further hydrolysis into shorter XOS and/or xylose. Studies have reported significant increases in the amount of FA released from arabinoxylan after the enzymatic hydrolysis by FAEs in the presence of xylanases [16-18]. Although FAEs from different microorganisms have been used for the co-production of FA and XOS, some of these FAEs show limited hydrolysis efficiencies. Therefore, novel FAEs with exceptional catalytic properties are still required for the formulation of more efficient enzyme cocktails.

Rashamuse and co-workers [19] functionally screened novel FAEs from the hindgut prokaryotic symbionts of Trinervitermes trinervoides termite species, but the application of these enzymes in degrading agricultural residues has not yet been explored. In this study, the synergistic action of two new termite metagenome derived FAEs (FAE5 and FAE6) and a GH11 xylanase from Thermomyces lanuginosus was optimized on insoluble wheat arabinoxylan (model substrate) and then applied to corn cobs (a natural substrate) for the production of XOS and hydroxycinnamic acids. The study presented demonstrated that high quantities of XOS, $p$-CA and FA were generated from corn cobs as a result of synergistic interactions between Xyn11 and FAE5 or FAE6.

\section{Materials and Methods}

\subsection{Chemicals, Substrates and Enzymes}

Escherichia coli BL21 (DE3) was used for the expression of fae5 and fae6 genes harboured in pET28 plasmids. The cells were cultured in Luria-Bertani (LB) medium containing $50 \mu \mathrm{g} / \mathrm{mL}$ kanamycin at $37^{\circ} \mathrm{C}$. The induction was conducted by following the method described previously [20]. Enzymes were purified using $5 \mathrm{~mL}$ Ni-NTA Superflow Cartridges (QIAGEN ${ }^{\circledR}$ ), purchased from QIAGEN (Germany), as per the manufacturer's instructions. Xylanase (Xyn11) from Thermomyces lanuginosus and ethyl ferulate (EFA) were purchased from Sigma Aldrich (South Africa). Insoluble wheat arabinoxylan (WAX) was purchased from Megazyme ${ }^{\mathrm{TM}}$ (Ireland). 


\subsection{Pre-Treatment of Corn Cobs}

Milled corn cobs (CC) was treated using hydrothermal pre-treatment or dilute acid pre-treatment. A total of $10 \mathrm{~g}$ of biomass was suspended in Milli-Q water (for hydrothermal treatment) or in a $0.5 \%$ $(w / w)$ sulphuric acid solution (for dilute acid treatment) (solid: liquid ratio of 1:10) and autoclaved for $20 \mathrm{~min}$ at $121^{\circ} \mathrm{C}$. The pre-treated CC slurry was filtered, followed by washing the solids repeatedly with Milli-Q water and then oven drying to constant weight at $50^{\circ} \mathrm{C}$ for $48 \mathrm{~h}$.

\subsection{Chemical Characterization of $C C$}

The total carbohydrates of CC were determined in triplicate by using a modified sulphuric acid method described previously [21]. Briefly, $300 \mathrm{mg}$ of CC (untreated and pre-treated) was hydrolyzed with $72 \%(v / v)$ sulphuric acid at $30{ }^{\circ} \mathrm{C}$ for $1 \mathrm{~h}$, diluted to $3 \%(v / v)$ sulphuric acid and autoclaved to solubilize the carbohydrate fraction. Following the hydrolysis, fractions were filtered to remove the insoluble lignin from the solution.

Determination of the alkali-extractable hydroxycinnamic acid content was carried out by treating $10 \mathrm{mg}$ of biomass with $1 \mathrm{M} \mathrm{NaOH}$ solution for $24 \mathrm{~h}$ at room temperature and in the dark. The liquors obtained from alkaline treatments were separated from the solid fraction by centrifugation at $16,000 \times g$ for $5 \mathrm{~min}$. The liquors were neutralized by 2 volumes of $1 \mathrm{M} \mathrm{HCl}$ and analyzed by HPLC as described in Section 2.4.

The morphological structure of untreated and pre-treated biomass was analyzed with a scanning electron microscope (SEM), JOEL JSM 840. CC samples were mounted on a metal stub with adhesive tape and coated with a thin layer of gold prior to SEM analysis.

In order to detect changes in functional groups, FTIR analysis of untreated and pre-treated CC was conducted by loading a few milligrams of pulverized samples in the universal ATR of a Spectrum 100 FT-IR spectrometer system (Perkin Elmer, Wellesley, MA). FT-IR spectra were recorded in quadruple at a range of $650-4000 \mathrm{~cm}^{-1}$ with a resolution of $4 \mathrm{~cm}^{-1}$.

\subsection{Determination of Enzyme Activities and Protein Concentration}

For feruloyl esterase activity assay, ethyl ferulate (EFA) was used as substrate. The reaction $(1 \mathrm{~mL})$ was carried out in sodium phosphate buffer $(50 \mathrm{mM}$, pH 7.4) that contained $1 \mathrm{mM}$ EFA. The reaction was initiated by the addition of a diluted enzyme solution. After $15 \mathrm{~min}$ incubation at $40^{\circ} \mathrm{C}$, the enzymatic activity was terminated by incubation at $100^{\circ} \mathrm{C}$ for $5 \mathrm{~min}$. The released FA from the substrate was quantified using a Shimadzu HPLC system (Shimadzu Corp, Japan) equipped with a diode array detector (DAD), where the chromatographic separation was achieved using a Phenomenex ${ }^{\circledR} C 185 \mu \mathrm{m}$ $(150 \times 4.6 \mathrm{~mm})$ LC column (Phenomenex, United States of America). Ambient conditions were used for analysis. The mobile phase A was $0.01 \mathrm{M}$ phosphoric acid and the mobile phase B consisted of HPLC grade acetonitrile. The isocratic mobile phase consisted of A: $70 \%$ and B: $30 \%$ and ran for $10 \mathrm{~min}$ at a flow rate of $0.8 \mathrm{~mL} / \mathrm{min}$. The injected volume was $10 \mu \mathrm{L}$ and the $\mathrm{UV}$ absorption of the effluent was monitored at $320 \mathrm{~nm}$. One unit of enzyme activity was defined as the amount of enzyme that released $1 \mu \mathrm{mol}$ of ferulic acid per min under standard conditions.

For xylanase activity assay, $10 \mathrm{mg} / \mathrm{mL}$ of insoluble wheat arabinoxylan (WAX) was used as a substrate. The reaction mixture consisted of $300 \mu \mathrm{L}$ of $1.33 \%(w / v)$ substrate dissolved in $50 \mathrm{mM}$ sodium phosphate buffer ( $\mathrm{pH} 7.4$ ) and $100 \mu \mathrm{L}$ of diluted enzyme. After $15 \mathrm{~min}$ incubation at $40^{\circ} \mathrm{C}$, the enzymatic activity was terminated by incubation at $100{ }^{\circ} \mathrm{C}$ for $5 \mathrm{~min}$, followed by centrifugation at $16,000 \times g$ for $5 \mathrm{~min}$. The concentrations of reducing sugar were measured using 3,5-dinitrosalicylic acid (DNS) method described previously [22]. Briefly, $150 \mu \mathrm{L}$ of the sample was mixed with $300 \mu \mathrm{L}$ of DNS followed by boiling for $5 \mathrm{~min}$. One unit of enzyme activity was defined as the amount of enzyme that released $1 \mu \mathrm{mol}$ of reducing sugars per min. Reducing sugars were estimated using a xylose standard curve. The yield of reducing sugars was determined using the following equation:

$$
\text { XOS yield }(\%)=((\text { XOS released } \times 0.88) / \text { xylan content }) \times 100
$$


The Bradford method was used to determine the protein concentration of the enzymes [23]. A protein standard curve was constructed using bovine serum albumin as a suitable standard.

\subsection{Synergy Studies}

In order to study the synergistic interactions on agricultural residues, the FAE and Xyn11 combinations were first tested on WAX for the release of FA and XOS. Enzyme loadings for all single enzymes and all enzyme combinations were kept at a total protein loading of $4 \mathrm{mg}$ protein per $\mathrm{g}$ of WAX and at $8 \mathrm{mg}$ per $\mathrm{g}$ of CC. For combination experiments, an enzyme mixture consisting of Xyn11 and FAE in a 66:33\% protein ratio was used. The enzymatic hydrolysis was performed at a substrate loading of $0.5 \%(w / v)$ for WAX and $1 \%(w / v)$ for CC in $50 \mathrm{mM}$ phosphate buffer $(\mathrm{pH} 7.4)$ in a total volume of $400 \mu \mathrm{L}$. The reaction mixture was incubated at $40^{\circ} \mathrm{C}$ with agitation at $25 \mathrm{rpm}$ for $24 \mathrm{~h}$ and terminated by boiling at $100{ }^{\circ} \mathrm{C}$ for $5 \mathrm{~min}$. Hydrolysis controls included reactions without the addition of enzyme or substrate. All the experiments were performed in triplicate. The amount of FA and $p$-CA released was determined using the HPLC method described in Section 2.4, while reducing sugars were measured using the DNS method and XOS were quantified using the HPLC-RID method described in Section 2.7 .

\subsection{Determination of Xylo-Oligosaccharides Pattern Profiles}

In order to determine the hydrolysis product profiles from synergy studies, XOS were analyzed by thin-layer chromatography (TLC). Five $\mu \mathrm{L}$ of hydrolysate sample and a mixture of XOS standards were applied on a silica gel $60 \mathrm{~F}_{254}$ plate (Merck, Darmstadt, Germany). The migration was repeated twice using a mobile phase consisting of 1-butanol, acetic acid and water in a 2:1:1 ratio, respectively. The plate was then submerged in Molisch's Reagent $(0.3 \%(w / v) \alpha$-naphthol dissolved in methanol and sulphuric acid in a 95:5 ratio $(v / v)$, respectively). The spots corresponding to the different XOS were visualized by heating the plate in the oven at $110^{\circ} \mathrm{C}$ for $10 \mathrm{~min}$.

The XOS were quantified by a Shimadzu HPLC system (Shimadzu Corp, Japan) equipped with a refractive index detector (RID) using a CarboSep CHO 411 column (Anatech, South Africa) with water as the mobile phase in isocratic mode. The column oven was set at $80^{\circ} \mathrm{C}$ and separation was performed within $35 \mathrm{~min}$ at a flow rate of $0.3 \mathrm{~mL}$ per min. An injection volume of $20 \mu \mathrm{L}$ was employed for all samples and XOS standards.

\subsection{Statistical Analysis}

All statistical analyses were performed on GraphPad Prism 6.0 software using the $t$-test. A $p$-value of less than 0.05 was considered to indicate statistically significant differences between compared data sets.

\section{Results}

\subsection{Chemical Characterization of CC}

The main hurdle in utilising lignocellulosic biomass lies in its recalcitrant nature due to the complexity of its biomass structure. Thus, to increase the enzymatic hydrolysis of biomass, various pre-treatment strategies are usually required. However, some of the pre-treatment methods are known for easily solubilizing some of the polysaccharides, mostly hemicellulose [24]. It is, therefore, critical to perform pre-treatment under conditions that lead to a recovery of the biomass components in a re-usable form while increasing the enzymatic digestibility. In this study, hydrothermal and dilute acid pre-treatment strategies were selected. An extremely low thermo-chemical pre-treatment severity was applied in order to preserve hemicellulose and hydroxycinnamic content in the solid fraction. In order to determine the effect and efficiency of the pre-treatments, the surface morphology of CC was visualized with SEM. Figure 1 shows the SEM micrographs of untreated and pre-treated CC. 


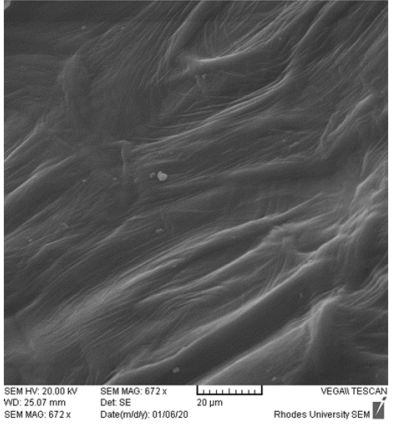

(a)

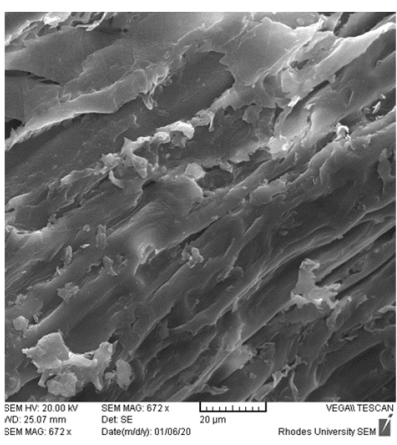

(b)

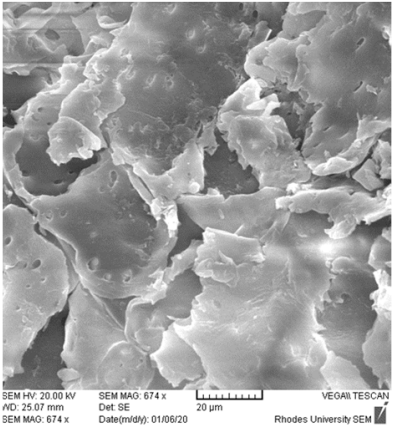

(c)

Figure 1. Morphological study of corn cobs (CC) by SEM. SEM micrographs of (a) untreated, (b) hydrothermal treated, and (c) acid-treated at a $2 \mathrm{k} \times$ magnification.

Here it can be seen that the untreated sample appears to possess a compact structure. In contrast, the micrographs of pre-treated CC samples display distorted and fragmented structures on the surface. The structural changes due to pre-treatment might increase the surface area of pre-treated CC, which could lead to an enhanced enzymatic degradability.

To determine the recoverable sugars and hydroxycinnamic acids after pre-treatment, the chemical composition of the untreated and pre-treated CC was also analyzed (Table 1). For noting, the composition of other CC components such as lignin was omitted, and attention was focused on glucan, xylan, arabinan, and hydroxycinnamic acids. The content of glucan, xylan, and arabinan was slightly higher in the pre-treated biomass compared to untreated biomass samples. There were more recoverable sugars in the hydrothermal treated sample compared to the acid pre-treated sample. A slight increase in FA and $p$-CA content was observed in the acid-treated sample. The data on Table 1 confirmed that the relevant CC components were successfully retained upon pre-treatment.

Table 1. Chemical composition of untreated and pre-treated CC (on a percentage dry mass basis).

\begin{tabular}{ccccccc}
\hline & Glucan $^{\mathbf{a}}$ & Xylan $^{\mathbf{a}}$ & Arabinan $^{\mathbf{a}}$ & $\begin{array}{c}\text { Reducing } \\
\text { Sugars }^{\mathbf{b}}\end{array}$ & FA $^{\mathbf{c}}$ & $\boldsymbol{p}^{-C A}{ }^{\mathbf{c}}$ \\
\hline $\begin{array}{c}\text { Untreated } \\
\text { Hydrothermal treated } \\
\text { Acid-treated }\end{array}$ & $30.86 \pm 0.90$ & $11.46 \pm 0.48$ & $7.79 \pm 0.63$ & $53.00 \pm 0.49$ & $0.61 \pm 0.012$ & $0.63 \pm 0.026$ \\
& $32.58 \pm 0.85$ & $12.22 \pm 0.48$ & $8.52 \pm 0.55$ & $59.20 \pm 0.15$ & $0.68 \pm 0.027$ & $0.67 \pm 0.013$ \\
\hline
\end{tabular}

Analysis method: ${ }^{a}$ Megazyme sugar kits, ${ }^{b}$ DNS method, ${ }^{c}$ HPLC. The data presented are averages \pm standard deviations of triplicates.

To further investigate the chemical changes that took place during the pre-treatment of CC, FTIR analysis was conducted. The spectra of untreated, hydrothermal and acid-treated CC are shown in Figure 2. The absorption peaks at around $1730 \mathrm{~cm}^{-1}$ region are predominantly attributed to the $\mathrm{C}=\mathrm{O}$ stretching vibration of the ester linkage of the carboxylic group of FA and $p$-CA of lignin and/or hemicellulose [25]. The spectra of all samples show this peak suggesting that changes due to pre-treatment (observed in SEM micrographs) did not lead to the removal of hemicellulose and hydroxycinnamic acids. The FTIR data is in agreement with composition analysis (Table 1), as the hydrothermal pre-treated sample displayed strong absorption bands around $1000 \mathrm{~cm}^{-1}$ and in the region 3500-3200 $\mathrm{cm}^{-1}$ (associated with $\beta$-glycosidic linkages and $\mathrm{OH}$ groups of glucose units, respectively) [26]. 


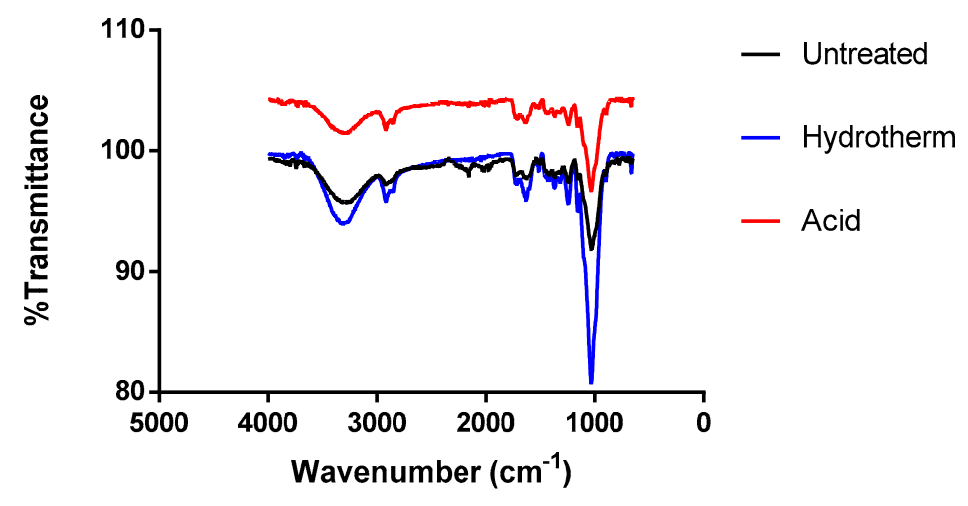

Figure 2. FTIR spectra of untreated, hydrothermal treated and acid-treated CC solids registered in the range of $450-4000 \mathrm{~cm}^{-1}$.

\subsection{Determination of Enzyme Specific Activities}

The specific activities of the enzymes used in this study were determined as detailed in Section 2.4 under Materials and Methods. Xyn11 was the only enzyme active on WAX with a specific activity of $15.08 \mathrm{U} / \mathrm{mg}$ of xylanase, while FAE5 and FAE6 showed activity only on EFA with specific activities of $28.36 \mathrm{U} / \mathrm{mg}$ and $27.34 \mathrm{U} / \mathrm{mg}$ of feruloyl esterase, respectively. FAE5 and FAE6 demonstrated relatively similar feruloyl esterase activities.

\subsection{Release of XOS from Substrates by Enzymatic Hydrolysis}

In order to evaluate synergistic interactions between FAEs and Xyn11 on untreated and pre-treated CC (agricultural residue), the enzymes were tested for their ability to release XOS and FA from a model arabinoxylan substrate (WAX). A $0.5 \%$ WAX substrate loading was used for a better comparison with natural substrates since they have xylan contents of between 20-40\%. Figure 3 shows the production of reducing sugars after enzymatic hydrolysis of WAX (a), untreated (b), hydrothermal treated (c) and acid-treated CC (d) by single or combinations of the enzymes. The trend in the production of reducing sugars was similar in all substrates, with the Xyn11 to FAE5/6 combinations releasing higher reducing sugars than those from the reactions containing individual enzymes. As expected, FAE5 or FAE6 alone were not able to release reducing sugars, this was also indicated in the specific activity determination study (Table 2). For hydrolysis of WAX (Figure 3a), both FAEs displayed synergy with Xyn11 by improving the release of reducing sugars. It was found that Xyn11 alone released $0.89 \mathrm{mg} / \mathrm{mL}$, while co-incubation with FAE5 or FAE6 resulted in $1.18 \mathrm{mg} / \mathrm{mL}(25.61 \%$ increase $)$ and $1.22 \mathrm{mg} / \mathrm{mL}$ reducing sugars (a $28.06 \%$ increase), respectively. The hydrolysis of untreated CC with xylanase alone and a combination of Xyn11 and FAE5 or FAE6 produced reducing sugars at concentrations of $0.94 \mathrm{mg} / \mathrm{mL}$, $1.17 \mathrm{mg} / \mathrm{mL}$, and $1.22 \mathrm{mg} / \mathrm{mL}$, respectively (Figure 3b). The hydrothermal pre-treated sample exhibited a similar hydrolysis pattern to untreated CC, but the amounts of reducing sugars released in the co-incubation sets were higher (Figure 3c). However, the amount of reducing sugars was significantly less for acid pre-treatment when Xyn11 was applied alone (yield of $28.80 \%$ ), but a combination of Xyn11 and FAE5 or FAE6 resulted in more reducing sugars (yield of $100 \%$ for both combinations) compared to untreated CC (Figure 3d). The hydrothermally pre-treated sample exhibited yields of $60.76 \%$ for Xyn11 alone, while co-incubation with FAE5 and FAE6 resulted in yields of $98.21 \%$ and $100 \%$, respectively. These results indicate that FAEs play an important role in the synergistic hydrolysis of WAX, and the arabinoxylan contained in untreated and pre-treated CC samples. 


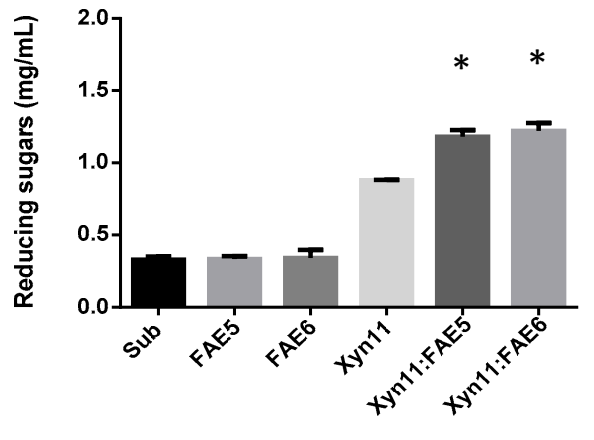

Enzyme combination

(a)

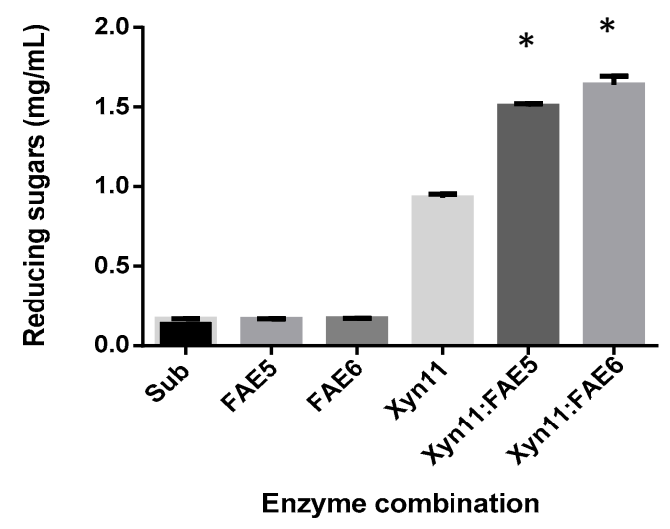

(c)

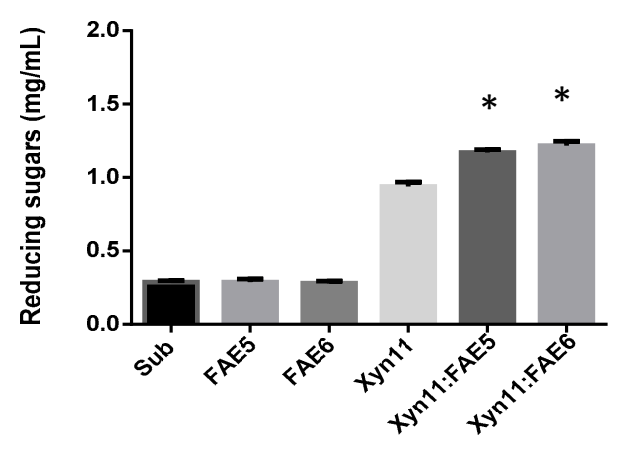

Enzyme combination

(b)

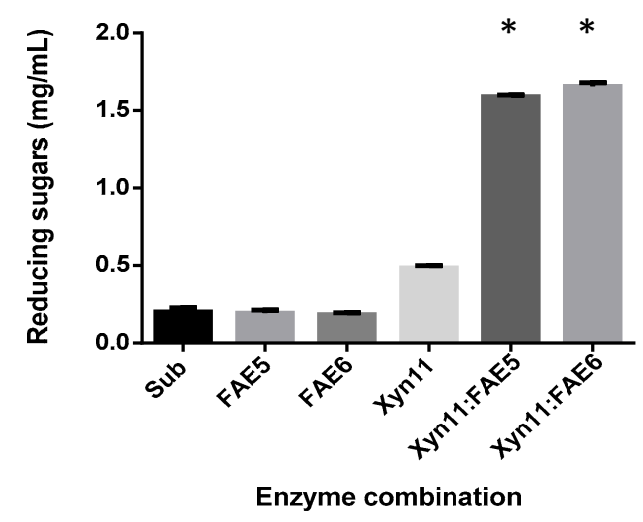

(d)

Figure 3. Release of reducing sugars during hydrolysis of $0.5 \%$ wheat arabinoxylan (WAX) (a), $1 \%$ untreated (b), hydrothermally pre-treated (c) and acid pre-treated CC (d) by individual enzymes or a combination of $66 \%$ Xyn11: 33\% FAE5 or FAE6. Sub represents substrate control. Statistical analysis was conducted using $t$-test for improvement of hydrolysis with respect to reducing sugar by the enzyme combinations compared to single enzyme $\left(\right.$ Xyn11), key: ${ }^{*}(p$ value $<0.05)$.

Table 2. Specific activities of the enzymes assessed in this study (U/mg protein).

\begin{tabular}{cccc}
\hline Substrate & Enzyme Tested & & \\
\hline & Xyn11 & FAE5 & FAE6 \\
WAX $^{\mathbf{a}}$ & 15.08 & $\mathrm{Nd}$ & $\mathrm{Nd}$ \\
EFA $^{\mathbf{b}}$ & $\mathrm{Nd}$ & 28.36 & 27.34
\end{tabular}

a Analyzed by 3,5-dinitrosalicylic acid (DNS) method for xylanase activity and ${ }^{\mathrm{b}}$ analyzed by HPLC diode array detector (DAD) for feruloyl esterase activity. "Nd" = not detected.

\subsection{Release of Hydroxycinnamic Acids from Substrates by Enzymatic Hydrolysis}

To further understand the synergism between Xyn11 and FAEs, the release of hydroxycinnamic acids from substrates by individual enzymes and their combinations was evaluated. Figure 4 shows the release of FA from WAX (a), untreated (b), hydrothermal pre-treated (c), and acid pre-treated treated CC (d). In the case of WAX (Figure 4a), a slight increase in FA release by FAE5 or FAE6 alone was observed. The combination of Xyn11 and FAE5 or FAE6 significantly improved $(p<0.05)$ the release of FA from $0.64 \mu \mathrm{g} / \mathrm{mL}$ and $0.65 \mu \mathrm{g} / \mathrm{mL}$ (individual enzyme) to $1.92 \mu \mathrm{g} / \mathrm{mL}$ and $2.68 \mu \mathrm{g} / \mathrm{mL}$, respectively. A similar pattern was observed for the hydrolysis of untreated CC, although a combination of Xyn11: FAE5 released more FA compared to Xyn11: FAE6 (Figure 4b). With respect to pre-treated CC, the amount of 
FA released from the substrate without enzymatic hydrolysis was enhanced (Figure 4c,d). This could be attributed to the disruption of the close inter-component associations between major constituents of lignocellulose during the pre-treatment step. Only Xyn11: FAE6 could significantly improve $(p<0.05)$ the release of FA from both pre-treated samples. The release of $p$-CA from CC was also observed and is shown in Figure 5. Similar to the results presented in Figure $4 c, d$, the pre-treated samples already showed increased amounts of readily soluble $p$-CA before enzymatic hydrolysis. However, the combination of Xyn11 and FAE5 or FAE6 were able to release considerable quantities of $p$-CA compared to individual enzymes and those already present and soluble in substrate controls. Interestingly, contrary to the FA release from pre-treated samples, both Xyn11: FAE5 and Xyn11: FAE6 could release comparable quantities of $p$-CA (Figure $5 b, c$ ). However, the yields obtained (no more than $10 \%$ ) were much less when compared to release efficiencies (more than 70\%) reported in some studies in the literature $[27,28]$. These results indicate that FAEs acted synergistically with Xyn11 in the co-production of XOS, FA and $p$-CA from the CC substrates.

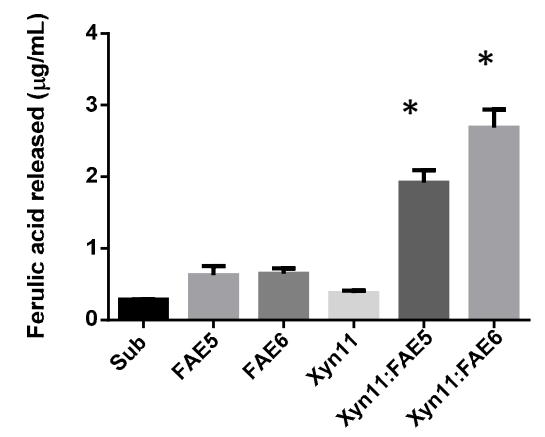

Enzyme combination

(a)

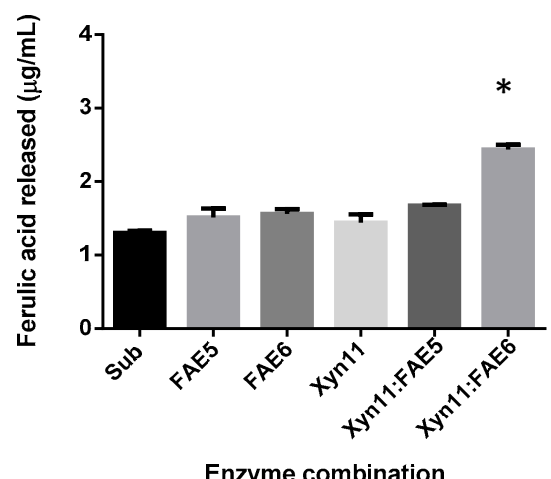

(c)

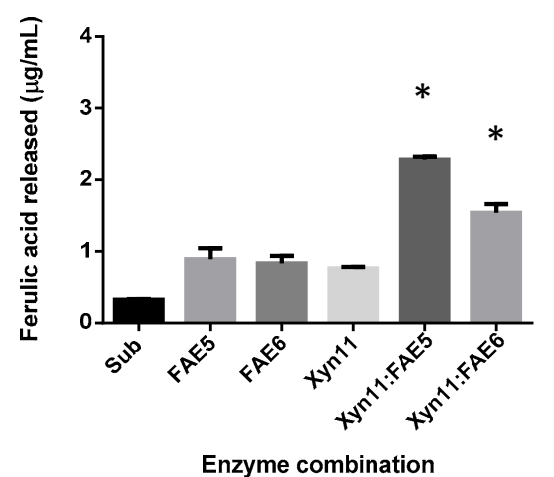

(b)

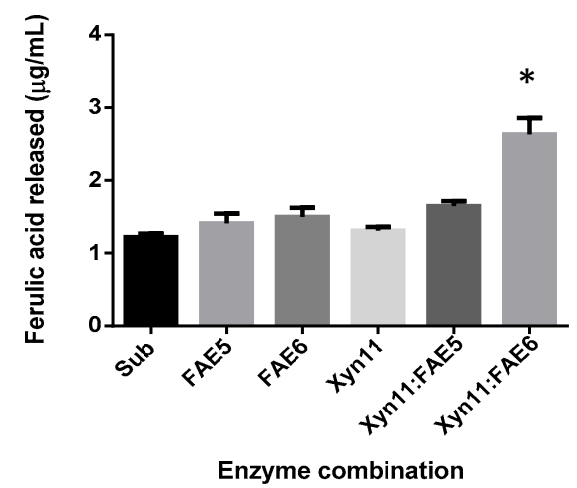

(d)

Figure 4. Release of ferulic acid during the degradation of $0.5 \%$ WAX (a), $1 \%$ untreated (b), hydrothermal pre-treated (c) and acid pre-treated CC (d) by individual enzymes or a combination of $66 \%$ Xyn11: $33 \%$ FAE5 or FAE6. Sub represents substrate control. Statistical analysis was conducted using $t$-test for improvement of Ferulic acid release by the enzyme combinations compared to single enzyme (FAE5/6), key: * $(p$ value $<0.05)$. 


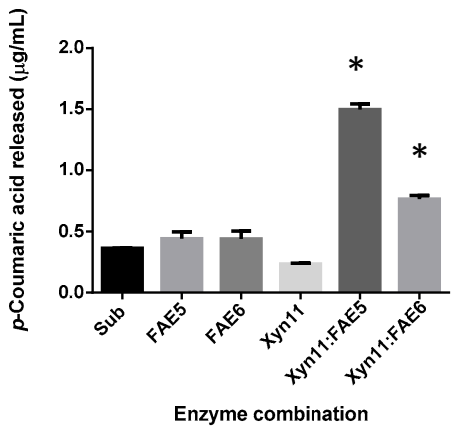

(a)

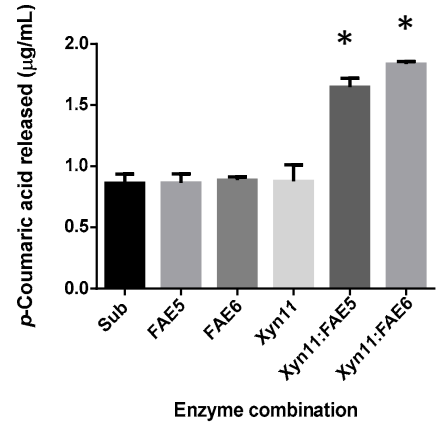

(b)

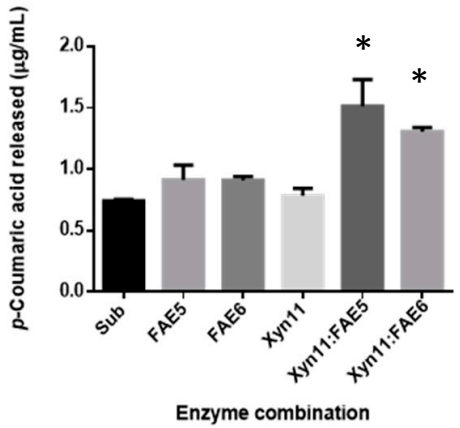

(c)

Figure 5. Release of $p$-coumaric acid during the degradation of $1 \%$ untreated (a), hydrothermal pre-treated (b) and acid pre-treated CC (c) by individual enzymes or a combination of $66 \%$ Xyn $11: 33 \%$ FAE5 or FAE6. Note, WAX was not assessed as there was no $p$-coumaric acid detected in the substrate. Sub represents substrate control. Statistical analysis was conducted using $t$-test for improvement of $p$-coumaric acid release by the enzyme combinations compared to single enzyme (FAE5/6), key: * $(p$ value $<0.05)$.

\subsection{Determination of Hydrolysate Product Profiles}

The data presented above indicates that FAE5 and FAE6 could release hydroxycinnamic acids in the presence of Xyn11 while improving the production of reducing sugars from WAX, untreated and pre-treated CC. To gain a deeper insight into these synergistic interactions, the product patterns of individual enzymes and their combinations were evaluated for the types of XOS generated. Figure 6 shows the TLC analysis of XOS released from the hydrolysis of WAX (a), untreated (b), hydrothermal treated (c) and acid-treated CC (d) by single and combinations of enzymes. It is important to note that the dark-yellow colored spots on the plates represent glycerol which was used as a stabilizer during storage of the purified FAE5 and FAE6. In the case of WAX hydrolysis (Figure 6a), individual enzymes (lane 2) and combinations (lane 3 and 4) generated xylobiose, xylotetraose, xylopentaose, and xylohexaose. The hydrolysis product patterns of CC (Figure $6 \mathrm{~b}-\mathrm{d}$ ) appeared to consist of xylobiose (a dominant product) and small quantities of xylotetraose. The quantities of xylobiose seem to increase for the treated CC, most especially for enzyme combinations (lane 3 and 4). Also, for acid pre-treated CC (Figure 6d), Xyn11 alone (lane 2) produced very small quantities of XOS, this was also observed in Figure $3 \mathrm{~b}$ during the quantification of reducing sugars.

We then further attempted to quantify the XOS generated using HPLC-RID. It is noteworthy that the HPLC-RID system used in this study couldn't detect XOS of less than $0.05 \mathrm{mg} / \mathrm{mL}$. Figure 7 shows that the quantity of xylobiose produced by the combination of Xyn11 and FAE5 or FAE6 was enhanced compared to Xyn11 alone, this pattern was more pronounced on untreated and pre-treated CC. High quantities of xylotetraose $(0.24 \mathrm{mg} / \mathrm{mL}$ ) were observed for WAX (Figure 7a), but there was no significant increase between individual enzymes and their combinations. The highest quantities of xylobiose were produced by enzyme combinations for hydrothermal pre-treated CC $(0.28 \mathrm{mg} / \mathrm{mL}$ for xyn11: FAE5 and $0.40 \mathrm{mg} / \mathrm{mL}$ for Xyn11: FAE6) and acid-treated CC $(0.34 \mathrm{mg} / \mathrm{mL}$ for Xyn11: FAE5 and $0.43 \mathrm{mg} / \mathrm{mL}$ for Xyn11: FAE6). This improvement in xylobiose production was significant $(p<0.05)$ when compared to single enzyme incubations, which resulted in $0.14 \mathrm{mg} / \mathrm{mL}$ and $0.12 \mathrm{mg} / \mathrm{mL}$ for hydrothermal and acid-treated CC, respectively. From the results presented above, it appears that Xyn11 produced XOS which become substrates to FAEs for the removal of FA or $p$-CA, and this allows Xyn11 to further hydrolyze these long XOS into the shorter xylobiose. 


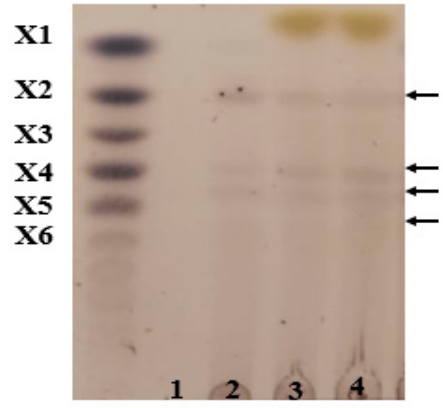

(a)

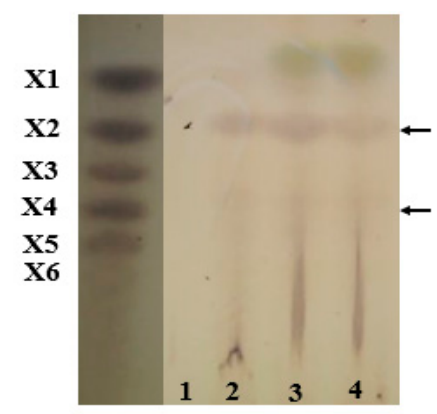

(c)

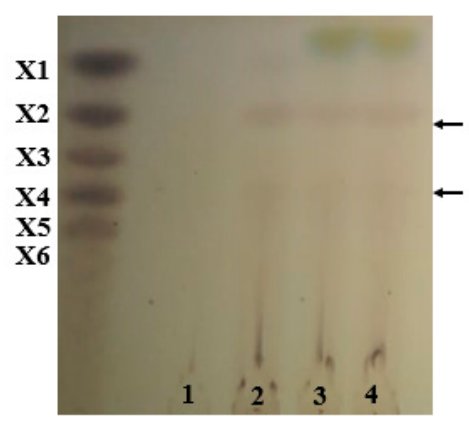

(b)

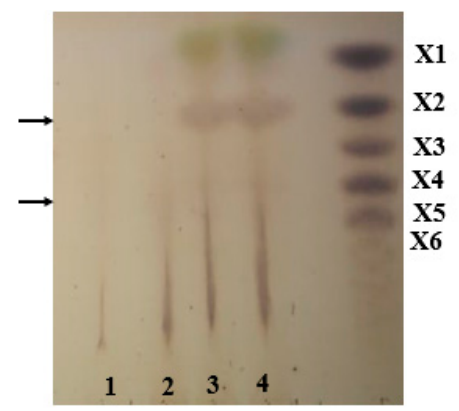

(d)

Figure 6. Thin-layer chromatography (TLC) analysis of hydrolysis of $0.5 \%$ WAX (a), $1 \%$ untreated (b), hydrothermal pre-treated (c) and acid pre-treated CC (d) by (2) Xyn11 alone, (3) a combination of $66 \%$ Xyn11: 33\% FAE5, and (4) a combination of 66\% Xyn11: 33\% FAE6. Substrate without enzyme was used as a control (1). A mixture of xylo-oligosaccharides (X1-X6) was used as a standard. Arrows indicated observed bands, albeit feint in some instances.

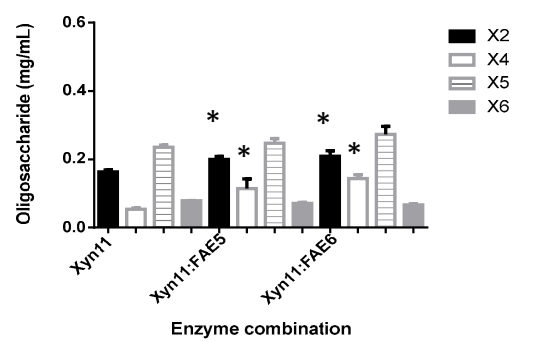

(a)

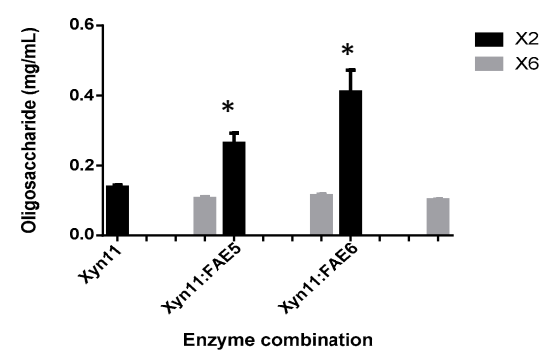

(c)

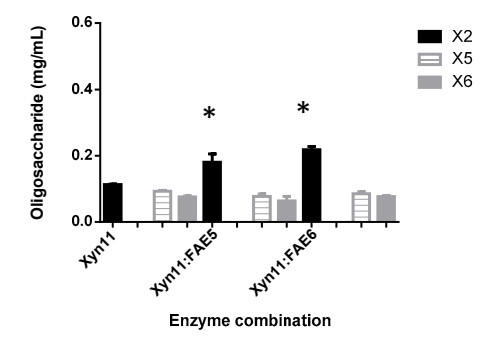

(b)

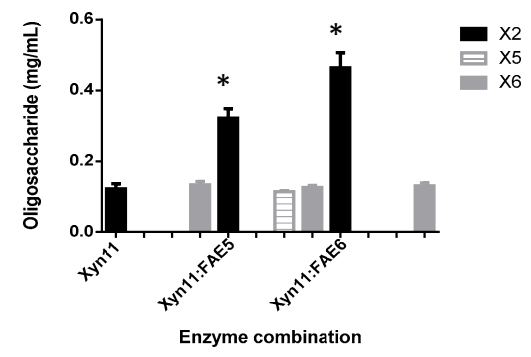

(d)

Figure 7. Xylo-oligosaccharide content measured from the hydrolysis of $0.5 \%$ WAX (a), $1 \%$ untreated (b), hydrothermal pre-treated (c) and acid pre-treated CC (d) after incubation with Xyn11 alone or a combination of $66 \%$ Xyn11: 33\% FAE5 or FAE6. Statistical analysis was conducted using $t$-test for improvement of hydrolysis with respect to xylo-oligosaccharides (XOS) by the enzyme combinations compared to single enzyme (Xyn11), key: * $(p$ value $<0.05)$. 


\section{Discussion}

XOS and high value-added compounds generated from agricultural residues have great potential for application in pharmaceutical, food, and fine chemical industries. It has been reported that the total world production of corn, a key agricultural crop, was estimated to exceed 875,226,630 tons [29]. $\mathrm{CC}$, a by-product of corn is an attractive agricultural residue due to its high xylan content and the fact that it's readily available. The production of XOS could be achieved by application of chemical and hydrothermal pre-treatments. However, higher severity pre-treatment conditions can lead to increased decomposition of XOS to xylose and generation of unwanted by-products [14]. The application of low severity pre-treatment conditions to increase accessible area for enzymes, followed by enzymatic hydrolysis, is an effective method for XOS production. In this study, the synergistic interactions between two termite metagenome-derived FAEs and a xylanase, Xyn11, for the production of XOS, $p$-CA and FA from untreated and pre-treated CC was evaluated. WAX was used as a model substrate to optimize the enzyme cocktail as it maintains the ferulic acid cross-linkages in the native arabinoxylan. CC was subjected to two pre-treatment strategies, hydrothermal and dilute sulfuric acid pre-treatment. The results for composition analysis (Table 1) showed that there was an increase in recoverable sugars and that hydroxycinnamic acid content was maintained in pre-treated samples. However, the xylan content of all samples was much less than the values reported in the literature (28\%) [30]. Biomass (morphology) characterization indicated that these changes were associated with increased surface area due to pre-treatment (Figure 1). It can be speculated that the increased sugar content of pre-treated CC samples (Table 1) may be due to these structural modifications which may include changes in lignin content. An increase in the production of reducing sugars was observed during enzymatic hydrolysis of pre-treated CC (Figure 3), indicating the success of the pre-treatment strategies selected for this study.

Regarding the enzymatic release of hydroxycinnamic acids from the substrates, the data presented above suggests that FAE5 or FAE6 could release significant amounts of FA and $p$-CA only in the presence of Xyn11. The inability of FAEs to release high quantities of hydroxycinnamic acids when incubated alone could be attributed to the type of bonds available on the substrate. FA or $p$-CA is usually found esterified to polysaccharides such as arabinoxylan and could also ether-link with lignin or dimerize with other hydroxycinnamic acid-linked polysaccharides, forming cross-linkages between these polymers. FAEs are known for specifically catalyzing the cleavage of ester bonds between hydroxycinnamic acids and polysaccharides, but not the ether-linkages. It is, therefore, possible that FAE5 and FAE6 couldn't act on these cross-linked complex structures. Previous studies have indicated that FAEs could release FA from substrates when co-incubated with xylanase [27,31]. Zhang and co-workers [32] reported that the combination of a xylanase and AfFaeA increased the amount of FA released from steam exploded corn stalk 13 -fold. It appears that FAE activity can be enhanced by the addition of a xylanase - it appears as if the xylanase generates feruloylated XOS from the xylan main chain which are easily hydrolyzed by FAE in comparison to feruloylated xylan. In turn, FAE action allows the xylanase to be able to further hydrolyze XOS with a high degree of polymerization into shorter chain XOS products. The patterns observed in the production of reducing sugars from acid pre-treated CC, presented in Figure 3d, are indicative of such a relationship between xylanase and FAE. The activity of Xyn11 alone was drastically reduced, while the enzyme combinations resulted in the highest reducing sugar release. It is likely acid pre-treatment of CC generated XOS esterified with FA or $p$-CA, which may pose limitations on their accessibility (steric hindrance) for the Xyn11 to hydrolyze them to shorter chain XOS products. Therefore, the addition of FAEs resulted in the improvement of Xyn11 activity on these long, feruloylated XOS. There have been reports on oligosaccharides resulting from the pre-treatment of several natural substrates [33-35].

The hydrolysis patterns of individual enzymes and enzyme combinations were then also investigated. Xyn11 and a combination of Xyn11 with FAEs released XOS with a low degree of polymerization (DP 6-4 and DP 2, respectively) from WAX and released mainly xylobiose from untreated and pre-treated CC. The variations in product patterns observed could be due to the 
differences in the xylan structure between WAX and CC. The yield of xylobiose from the pre-treated substrates was significantly increased by enzyme combinations compared to individual enzymes. It has been reported that xylobiose rich XOS are the preferred products for prebiotic activity [36]. The product patterns demonstrated that the Xyn11: FAEs enzyme combination (cocktail) has the potential of releasing XOS with a high xylobiose content from CC, most notably when combined with hydrothermal or dilute sulfuric acid pre-treatments.

\section{Conclusions}

This study reported, for the first time, the application of two termite metagenome-derived FAEs for the production of XOS and hydroxycinnamic acids from CC. The FA and/or $p$-CA released from WAX and CC was greatly enhanced when FAE5 and FAE6 were co-incubated with Xyn11 compared to when the enzymes were applied individually. The presence of FAEs played a major role in the production of XOS, mainly xylobiose, from untreated and pre-treated CC. This study suggests that FAEs act synergistically with Xyn11 during the enzymatic hydrolysis of CC to produce the industrially relevant products $\mathrm{XOS}$ and hydroxycinnamic acids.

Author Contributions: Conceptualization, L.M.; S.M.; B.S.W. and B.I.P.; methodology, L.M.; software, L.M.; validation, L.M.; S.M.; B.S.W. and B.I.P.; formal analysis, L.M.; S.M.; B.S.W. and B.I.P.; investigation, L.M.; resources, B.S.W. and B.I.P.; data curation, L.M.; writing-original draft preparation, L.M.; writing-review and editing, L.M.; S.M.; B.S.W. and B.I.P.; visualization, L.M.; supervision, B.I.P. and B.S.W.; project administration, B.I.P. and B.S.W.; funding acquisition, B.I.P. All authors have read and agree to the published version of the manuscript.

Funding: The work was funded by the South African Department of Science and Technology (DST)/Council for Scientific and Industrial Research (CSIR) National Biocatalysis Initiative, National Research Foundation (NRF) of South Africa and Rhodes University. Any opinion, findings and conclusions or recommendations expressed in this material are those of the author(s) and therefore the NRF does not accept liability in regard thereto.

Conflicts of Interest: The authors declare no conflict of interest.

\section{References}

1. Kang, Q.; Appels, L.; Tan, T.; Dewil, R. Bioethanol from lignocellulosic biomass: Current findings determine research priorities. Sci. World J. 2014, 2014, 1-13. [CrossRef] [PubMed]

2. Anwar, Z.; Gulfraz, M.; Irshad, M. Agro-industrial lignocellulosic biomass a key to unlock the future bio-energy: A brief review. J. Radiat. Res. Appl. Sci. 2014, 7, 163-173. [CrossRef]

3. Van Dyk, J.S.; Pletschke, B.I. A review of lignocellulose bioconversion using enzymatic hydrolysis and synergistic cooperation between enzymes-Factors affecting enzymes, conversion and synergy. Biotechnol. Adv. 2012, 30, 1458-1480. [CrossRef] [PubMed]

4. Wong, D.W.S. Feruloyl esterase: A key enzyme in biomass degradation. Appl. Biochem. Biotechnol. 2006, 133, 87-112. [CrossRef]

5. Faulds, C.B. What can feruloyl esterases do for us? Phytochem. Rev. 2009, 9, 121-132. [CrossRef]

6. Oliveira, D.M.; Finger-Teixeira, A.; Mota, T.; Salvador, V.H.; Moreira-Vilar, F.C.; Molinari, H.B.C.; Mitchell, R.; Marchiosi, R.; Ferrarese-Filho, O.; Dos Santos, W.D. Ferulic acid: A key component in grass lignocellulose recalcitrance to hydrolysis. Plant Biotechnol. J. 2014, 13, 1224-1232. [CrossRef]

7. Pei, K.; Ou, J.; Huang, J.; Ou, S. p-Coumaric acid and its conjugates: Dietary sources, pharmacokinetic properties and biological activities. J. Sci. Food Agric. 2016, 96, 2952-2962. [CrossRef]

8. Kumar, N.; Pruthi, V. Potential applications of ferulic acid from natural sources. Appl. Biotechnol. Rep. 2014, 4, 86-93. [CrossRef]

9. Shirai, A.; Matsuki, H.; Watanabe, T. Inactivation of foodborne pathogenic and spoilage micro-organisms using ultraviolet-A light in combination with ferulic acid. Lett. Appl. Microbiol. 2017, 64, 96-102. [CrossRef]

10. Chen, X.; Guo, Y.; Jia, G.; Zhao, H.; Liu, G.; Huang, Z. Ferulic acid regulates muscle fiber type formation through the Sirt1/AMPK signaling pathway. Food Funct. 2019, 10, 259-265. [CrossRef]

11. Oliveira, D.M.; Mota, T.R.; Oliva, B.; Segato, F.; Marchiosi, R.; Ferrarese-Filho, O.; Faulds, C.; Dos Santos, W.D. Feruloyl esterases: Biocatalysts to overcome biomass recalcitrance and for the production of bioactive compounds. Bioresour. Technol. 2019, 278, 408-423. [CrossRef] [PubMed] 
12. Paës, G.; Berrin, J.-G.; Beaugrand, J. GH11 xylanases: Structure/function/properties relationships and applications. Biotechnol. Adv. 2012, 30, 564-592. [CrossRef] [PubMed]

13. Aachary, A.A.; Prapulla, S.G. Xylooligosaccharides (XOS) as an emerging prebiotic: Microbial synthesis, utilization, structural characterization, bioactive properties, and applications. Compr. Rev. Food Sci. Food Saf. 2010, 10, 2-16. [CrossRef]

14. Samanta, A.; Jayapal, N.; Jayaram, C.; Roy, S.; Kolte, A.; Senani, S.; Sridhar, M. Xylooligosaccharides as prebiotics from agricultural by-products: Production and applications. Bioact. Carbohydr. Diet. Fibre 2015, 5, 62-71. [CrossRef]

15. Malgas, S.; Mafa, M.S.; Mkabayi, L.; Pletschke, B. A mini review of xylanolytic enzymes with regards to their synergistic interactions during hetero-xylan degradation. World J. Microbiol. Biotechnol. 2019, 35, 187. [CrossRef] [PubMed]

16. Dilokpimol, A.; Mäkelä, M.R.; Mansouri, S.; Belova, O.; Waterstraat, M.; Bunzel, M.; De Vries, R.P.; Hildén, K. Expanding the feruloyl esterase gene family of Aspergillus niger by characterization of a feruloyl esterase, FaeC. New Biotechnol. 2017, 37, 200-209. [CrossRef]

17. Mäkelä, M.R.; Dilokpimol, A.; Koskela, S.; Kuuskeri, J.; De Vries, R.P.; Hildén, K. Characterization of a feruloyl esterase from Aspergillus terreus facilitates the division of fungal enzymes from Carbohydrate Esterase family 1 of the carbohydrate-active enzymes (CAZy) database. Microb. Biotechnol. 2018, 11, 869-880. [CrossRef]

18. Lau, T.; Harbourne, N.; Oruña-Concha, M.J. Optimization of enzyme-assisted extraction of ferulic acid from sweet corn cob by response surface methodology. J. Sci. Food Agric. 2019, 100, 1479-1485. [CrossRef]

19. Rashamuse, K.; Ronneburg, T.; Sanyika, W.; Mathiba, K.; Mmutlane, E.; Brady, D. Metagenomic mining of feruloyl esterases from termite enteric flora. Appl. Microbiol. Biotechnol. 2013, 98, 727-737. [CrossRef]

20. Beukes, N.; Pletschke, B.I. Effect of lime pre-treatment on the synergistic hydrolysis of sugarcane bagasse by hemicellulases. Bioresour. Technol. 2010, 101, 4472-4478. [CrossRef]

21. Sluiter, J.B.; Ruiz, R.O.; Scarlata, C.J.; Sluiter, A.D.; Templeton, D. Compositional Analysis of Lignocellulosic Feedstocks 1: Review and Description of Methods. J. Agric. Food Chem. 2010, 58, 9043-9053. [CrossRef]

22. Miller, G.L. Use of dinitrosalicylic acid reagent for the determination of reducing sugars. Anal. Chem. 1959, 31, 426-428. [CrossRef]

23. Bradford, M.M. A rapid and sensitive method for the quantitation of microgram quantities of protein utilizing the principle of protein-dye binding. Anal. Biochem. 1976, 72, 248-254. [CrossRef]

24. Rabemanolontsoa, H.; Saka, S. Various pretreatments of lignocellulosics. Bioresour. Technol. 2016, 199, 83-91. [CrossRef] [PubMed]

25. Gabhane, J.; William, S.P.; Vaidya, A.N.; Das, S.; Wate, S.R. Solar assisted alkali pretreatment of garden biomass: Effects on lignocellulose degradation, enzymatic hydrolysis, crystallinity and ultra-structural changes in lignocellulose. Waste Manag. 2015, 40, 92-99. [CrossRef] [PubMed]

26. Chandra, C.S.J.; George, N.; Narayanankutty, S.K. Isolation and characterization of cellulose nanofibrils from arecanut husk fibre. Carbohydr. Polym. 2016, 142, 158-166.

27. Wu, H.; Li, H.; Xue, Y.; Luo, G.; Gan, L.; Liu, J.; Mao, L.; Long, M. High efficiency co-production of ferulic acid and xylooligosaccharides from wheat bran by recombinant xylanase and feruloyl esterase. Biochem. Eng. J. 2017, 120, 41-48. [CrossRef]

28. Levasseur, A.; Navarro, D.; Punt, P.J.; Belaich, J.-P.; Asther, M.; Record, E. Construction of engineered bifunctional enzymes and their overproduction in aspergillus niger for improved enzymatic tools to degrade agricultural by-products. Appl. Environ. Microbiol. 2005, 71, 8132-8140. [CrossRef]

29. Ranum, P.; Peña-Rosas, J.P.; Garcia-Casal, M.N. Global maize production, utilization, and consumption. Ann. N. Y. Acad. Sci. 2014, 1312, 105-112. [CrossRef]

30. Da Silva, J.C.; De Oliveira, R.C.; Neto, A.D.S.; Pimentel, V.C.; Santos, A.D.A.D. Extraction, addition and characterization of hemicelluloses from corn cobs to development of paper properties. Procedia Mater. Sci. 2015, 8, 793-801. [CrossRef]

31. Nieter, A.; Kelle, S.; Linke, D.; Berger, R.G. Feruloyl esterases from Schizophyllum commune to treat food industry side-streams. Bioresour. Technol. 2016, 220, 38-46. [CrossRef] [PubMed]

32. Zhang, S.-B.; Zhai, H.-C.; Wang, L.; Yu, G. Expression, purification and characterization of a feruloyl esterase A from Aspergillus flavus. Protein Expr. Purif. 2013, 92, 36-40. [CrossRef] [PubMed] 
33. Appeldoorn, M.M.; De Waard, P.; Kabel, M.A.; Gruppen, H.; Schols, H.A. Enzyme resistant feruloylated xylooligomer analogues from thermochemically treated corn fiber contain large side chains, ethyl glycosides and novel sites of acetylation. Carbohydr. Res. 2013, 381, 33-42. [CrossRef]

34. Jonathan, M.; DeMartini, J.; Thans, S.V.S.; Hommes, R.; Kabel, M.A. Characterisation of non-degraded oligosaccharides in enzymatically hydrolysed and fermented, dilute ammonia-pretreated corn stover for ethanol production. Biotechnol. Biofuels 2017, 10, 112. [CrossRef] [PubMed]

35. Bhatia, L.; Sharma, A.; Bachheti, R.K.; Chandel, A.K. Lignocellulose derived functional oligosaccharides: Production, properties, and health benefits. Prep. Biochem. Biotechnol. 2019, 49, 744-758. [CrossRef] [PubMed]

36. Singh, R.D.; Banerjee, J.; Sasmal, S.; Muir, J.; Arora, A. High xylan recovery using two stage alkali pre-treatment process from high lignin biomass and its valorization to xylooligosaccharides of low degree of polymerisation. Bioresour. Technol. 2018, 256, 110-117. [CrossRef]

(C) 2020 by the authors. Licensee MDPI, Basel, Switzerland. This article is an open access article distributed under the terms and conditions of the Creative Commons Attribution (CC BY) license (http://creativecommons.org/licenses/by/4.0/). 